\title{
'Milk of calcium' in the breast
}

\author{
Filipe Veloso Gomes, ${ }^{1}$ Maria Joana Rebelo Almeida, ${ }^{2}$ Jose Carlos Marques ${ }^{3}$ \\ ${ }^{1}$ Department of Radiology, Hospital de Faro, Faro, Portugal \\ ${ }^{2}$ Department of Radiology, Hospital Curry Cabral, Lisboa, Portugal \\ ${ }^{3}$ Department of Radiology, Instituto Portugues Oncologia, Lisbon, Portugal \\ Correspondence to Dr Filipe Veloso Gomes, fvgomes@gmail.com
}

\section{DESCRIPTION}

Milk of calcium in the breast consists of calcium deposits within microcysts, and it is found in $4-6 \%^{1}$ of all women undergoing mammography. It is important to recognise its characteristic features in order to avoid unnecessary biopsy (figure 1$)^{2}$

Mammographic appearance is pathognomonic of this benign entity (figure 2). ${ }^{1}$ Characteristically, calcium particles within cysts produce linear, curved or 'teacup'-shaped calcifications on medio-lateral oblique or true lateral (TL) views, which clearly change their shape on craniocaudal (CC) views, where the vertical x-ray beam shows smudged calcifications (figure 3). ${ }^{3}$ This is explained by the deposition of calcium particles at the bottom of the microcysts due to gravity. ${ }^{1}$

A 44-year-old woman was referred to our breastimaging department because of the finding of suspicious breast microcalcifications (BI-RADS 4), after voluntary mammography screening in the community. A single cluster of microcalcifications, located in the upper outer quadrant of the right breast on repeat TL and CC magnified views was typical of milk of calcium. The lesion was classified as BI-RADS 2, and the patient was reassured without biopsy.

\section{CONCLUSION}

Mammographic analysis requires expertise and the general principle of biopsying any suspicious or uncertain findings should prevail. Milk of calcium is a relatively common finding, shown to be benign on prolonged follow-up, ${ }^{1}$ and likely to present at any moderately busy breast-imaging department as a potential cause for unnecessary biopsy. Biopsy should not be performed in such cases, though care should be taken not to miss any suspicious lesions, either in the vicinity or away from the lesion.

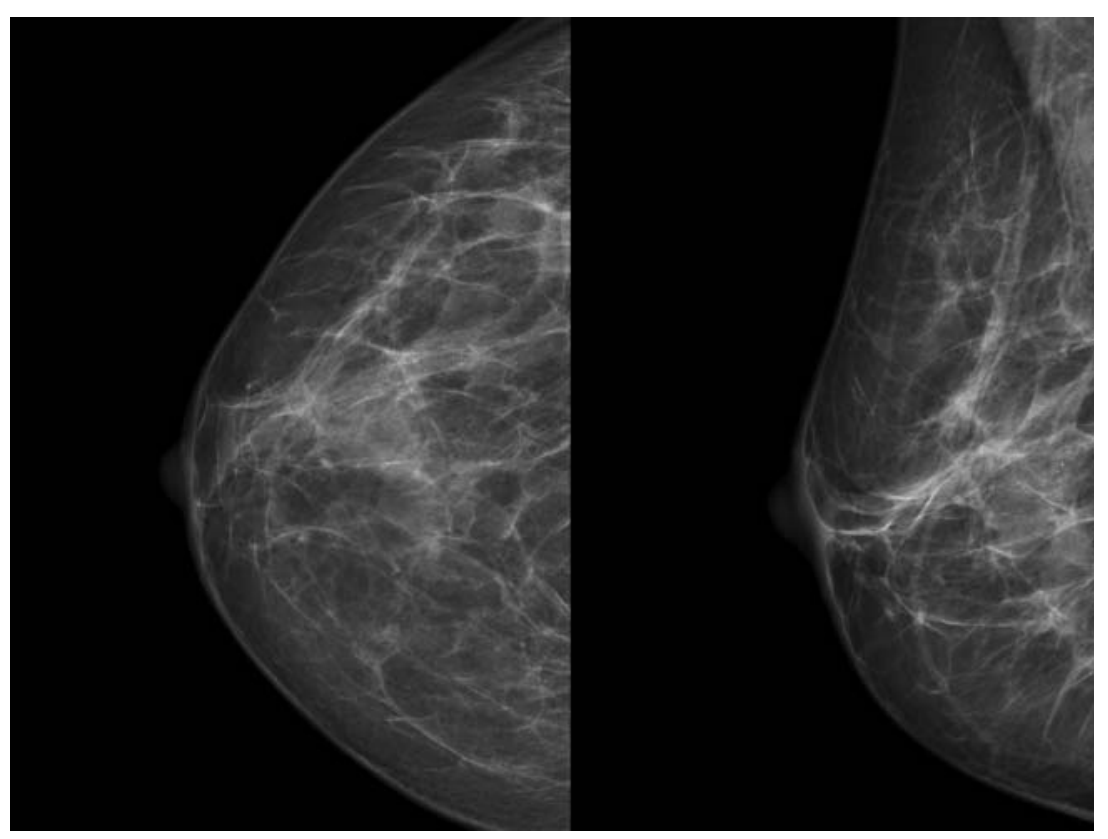

Figure 1 Craniocaudal and medio-lateral oblique mammographic views showing a single cluster of microcalcifications located in the outer quadrants of the right breast. 


\section{BMJ Case Reports}

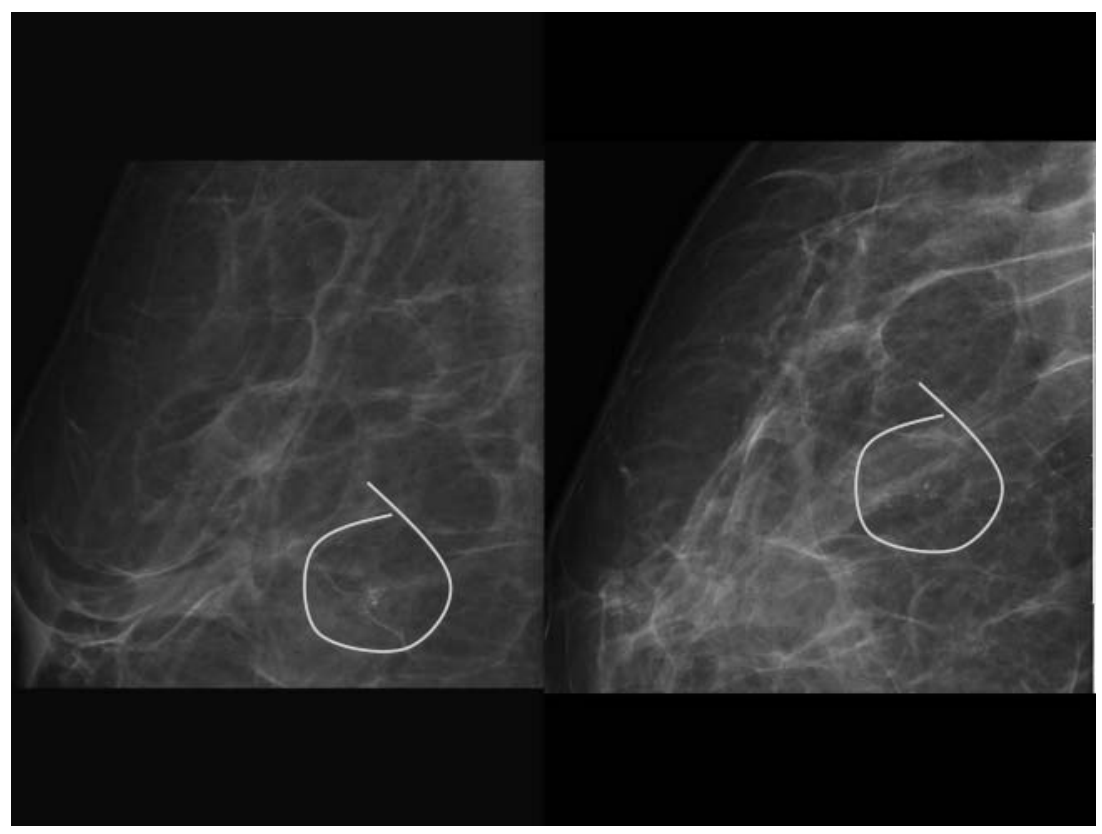

Figure 2 Mammographic views showing the 'teacup'-shaped microcalcifications on macro true lateral view and smudged calcifications on macro craniocaudal view.

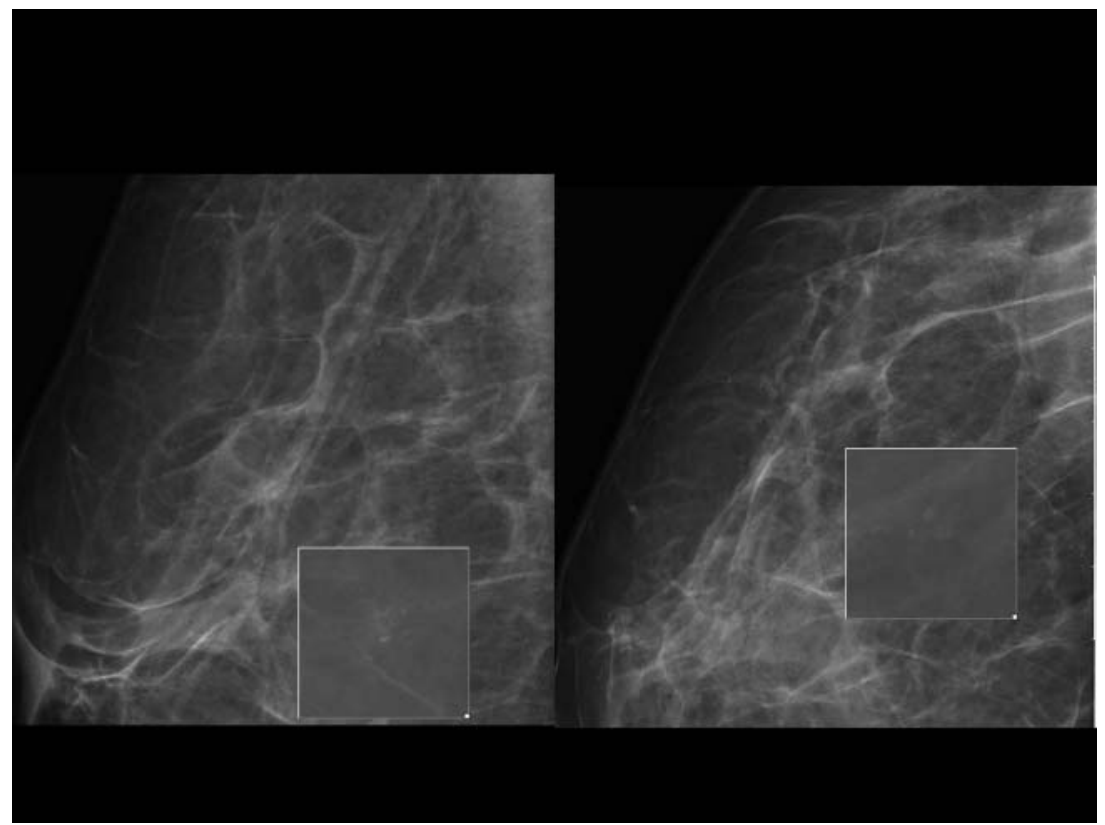

Figure 3 Magnification of mammographic views showing the 'teacup'-shaped microcalcifications on macrotrue lateral view and smudged calcifications on macro craniocaudal view.

\section{Learning points}

- Suspicious breast microcalcifications should always be biopsied.

- "Milk of Calcium" type microcalcifications have been shown to be benign with prolonged follow-up, and shoud not be biopsied.

- Benign and suspicious microcalcifications can occur simultaneously, and the latter should be biopsied.

\section{Competing interests None.}

Patient consent Obtained.

\section{REFERENCES}

1. Linden S, Sickles E. Sedimented calcium in benign brest cysts: the full spectrum of mammographic presentations. AJR 1989;152:967-71.

2. Homer $\mathbf{M}$, Cooper $A$, Pile-Spellman E. Milk of calcium in breast microcysts: manifestation as a solitary focal disease. AJR 1988;150:789-90.

3. Moy L, Slanetz P, Yeh E, et al. The pendent view: an additional projection to confirm milk of calcium. AJR 2001:177:173-5. 
This pdf has been created automatically from the final edited text and images.

Copyright 2012 BMJ Publishing Group. All rights reserved. For permission to reuse any of this content visit http://group.bmj.com/group/rights-licensing/permissions.

BMJ Case Report Fellows may re-use this article for personal use and teaching without any further permission.

Please cite this article as follows (you will need to access the article online to obtain the date of publication).

Veloso Gomes F, Almeida MJR, Marques JC. 'Milk of calcium' in the breast. BMJ Case Reports 2012;10.1136/bcr-11-2011-5119, Published XXX

Become a Fellow of BMJ Case Reports today and you can:

- Submit as many cases as you like

- Enjoy fast sympathetic peer review and rapid publication of accepted articles

- Access all the published articles

- Re-use any of the published material for personal use and teaching without further permission

For information on Institutional Fellowships contact consortiasales@bmjgroup.com

Visit casereports.bmj.com for more articles like this and to become a Fellow 